\title{
Research of Second Language Teaching under Constructivism
}

\author{
Wenping $\mathrm{Fu}^{1}$ \\ ${ }^{1}$ Xi'an International University, Xi'an, Shaanxi, 710065 \\ 346591653@163.com
}

KEYWORDS: Constructivism; Second language Teaching; Countermeasure

\begin{abstract}
Two theoretical study of language teaching has been the focus of attention of the education sector. In the process of second language teaching, teachers need to adopt effective teaching mode and teaching methods. Second language teaching as an important part of learning need to pay attention to the theoretical foundation, while choosing appropriate teaching theory as a guide, to ensure the quality of second language teaching. The constructivist theory to second language teaching, the use of knowledge Constructivism, learning and teaching, and guiding a second language teaching, not only to provide a theoretical basis for future research, but also for the second language teaching and research work presents a more reasonable teaching theory and teaching mode, and ultimately enhance the level of a second language, language training more personnel.
\end{abstract}

\section{Introduction}

Different from the traditional concept of teaching, based on second language teaching under constructivism has more obvious advantages. Traditional teaching is teacher-led, although the emotional communication between teachers and students are more diverse, but the entire single second language learning environment, the students played more instill a knowledge of objects, plus the lack of independence of the traditional teaching students, autonomous thinking, closed the entire teaching process, poor teaching. The use of constructivist theory, with its rich theoretical basis of teaching has a more positive meaning.

\section{The Theory of Constructivism}

In essence, it belongs to a constructivist epistemology. Richardson scholars view that Constructivism is a theory of knowledge, learning and a theory about the construction of meaning. From the point of view of the level of learning theory, learning theory is the core of constructivism, this level that the student in the learning process Why concern. This construction process is not knowledge transfer in the traditional sense, but rather relies on students to be active construction of knowledge.

Constructivism complex sources, different perspectives on constructivism have different classification. In education, it is mainly reflected in three aspects. Constructivism in personal view is that knowledge in an individual state. Emphasizes cognitive adaptation to the world and individual Construction Mode, that knowledge is active construction. There are two principles of radical constructivism, first, the construction process is under the old and new knowledge of the interactions occur. Second, all knowledge is built up in the course of the individual and the experience of. In these two points as the basis for the radical constructivism is more emphasis on 
the interaction between the individual and the physical environment, with respect to the social importance of the study is not enough. Social Constructivism is both personal and radical constructivism perfected on the basis of progressive development, in which the characters must improve - Language Acquisition Theory Vygotsky proposed is to improve the theoretical basis of social constructivism important section. Therefore, from this point of view of social constructivism, it is that knowledge and learning in a certain social and cultural background, regardless of what kind of social practice is a source of knowledge. Thus, learning occurs not only on the individual, but also occurs in social activities.

\section{The Application of Second Language Theory under Constructivism}

Constantly improve the constructivist theory there are several relatively perfect teaching. For these types of Teaching Model and second language teaching, teaching quality, teaching effectiveness will have some impact.

First, scaffolding. The differentiation of complex learning tasks so that learners have a gradual process in the learning process. Scaffolding Instruction is from the construction industry extends from scaffolding, in the image of the teaching were illustrated as a teaching mode, via a bracket so that the horizontal guide students to a higher level.

Second, anchored. This teaching model is to enable students in a real and complete context of the problem to feel, experience, pay more attention to the students in such a process is a proactive, rather than passive acceptance of traditional teaching teachers to instill knowledge. In this process, students automatically generate demand for knowledge, while learning to achieve goals through cooperative learning students and between students.

Third, the random access type. This way both described above has some similar place. Due to the complexity and multi-faceted learning a second language learner can not learn things to achieve a comprehensive understanding and grasp of the state. Therefore, to improve learning efficiency, learners can freely randomly in different ways, in different ways into the same second language learning process, so as to obtain a second language multifaceted understanding. In order to better improve the quality of teaching a second language, conduct research on the instance is necessary.

\section{The Countermeasures of Second Language Teaching under Constructivism}

Constructivism and second language teaching connect together, so that the theoretical basis of second language teaching is even more perfect. In constructivist learning environment, situation, cooperation, conversation and meaning construction of the four constituent elements. Under constructivism second language teaching with emphasis on contextual, interactive, autonomous, English as a second language for the case study:

In Higher Education, for example, in the teaching process, we can first use of anchored teaching model to create situations in the way, in the teaching process can begin in a number of internationally renowned institutions of higher learning image displayed. After one cycle through the images, specifically to enable students to appreciate the teachers each picture and ask students to understand the combination of building speculation is which university. (Students while thinking while browsing process, some students said the University of Cambridge, because the picture is clear architectural style English style) when students make their own opinion after the teacher announced the answer. After completing the picture suspicion this link, and then throw the problem of teachers, and students are encouraged to cooperate by way of group discussion to verify the answer, in which students' interaction process, students learn more knowledge, teachers play the 
video after the completion of group discussion data. Then, the teacher plays some hearing information for students according to the amount of trauma situation prompted teachers to understand the content of the hearing, conducted Meaning Construction. After listening to students, teachers make again group work content summary hearing information between students.

In such a process, through the use of multimedia technology create a rich image of the situation, not only to give a visual impact on the learner, but also can effectively stimulate students' enthusiasm for learning. In this environment, the real second language learners collaborate using active construction completed a new way of learning new knowledge Construction.

Use Scaffolding Instruction guide students to actively participate in the learning. By teaching content so that students and between students and maintain an effective interaction between students and teachers, reflecting the advantages of cooperative learning. In this process, the main role of the teacher is to guide, encourage students to discuss and contacts. Students in active construction process, teachers need to provide students with some learning materials, the use of the creation of an effective way of problem situations, students take the initiative to promote the construction of knowledge. The whole process should not only focus on individual teachers' enthusiasm in learning process, but also to urge cooperation between the entire team to ensure that the entire teaching environment is in a good condition.

When the process is during group work discussions, teachers can use multimedia exhibit some sentences or structural formula reminders. Students in the course of discussions with each other can be corrected according to the teacher's reminder. Warm-up on the back of knowledge is to enable students to have a basic understanding of this class.

Next, the teacher will be ready courseware displayed, implementation language, screen, visual, auditory integration, greatly stimulated the enthusiasm of the students. In a second language listening teaching English as an example to Shopping theme, when students complete the warm-up, into the difficult essay hearing. Teachers can use multimedia related language and cultural background material displayed, use this section to also use multimedia to constructivism in social interaction, it reflects this moment is to learn social and cultural. Because learning a language is not only master the language, but also need to understand the language and cultural contacts. Therefore, teachers in the teaching process should make full use of this, during playback listening material, and shopping related vocabulary teachers were focused on cultural background to explain. After completion of hearing all learning content, teachers allow students to form study groups, using role-playing, which allows students to construct a shopping context. In this process, students will use what they have learned it, so I heard with one.

In this way students learn not only to knowledge of the language, while improving the listening and speaking skills, but also improve the communicative competence. Although it is impossible to create a truly English language teaching in the classroom environment, but this is also a way to create situations to achieve a certain effect.

In Festival, for example, it is to arrange teacher prep tasks. Students also belong to preview a self-learning. Teachers need a good layout before making teaching-related tasks preview. On the prep tasks for Faculty deliberately chose several resource-rich holiday. This process requires teachers to student appropriate guidance. When students complete preparation, teachers need prep random checks of students in the classroom situation. Ask students while checking whether or not a student record relevant information. We found that some students recorded directly related to different cultural backgrounds of the festival, there are some students use the Internet directly into PPT courseware, including a variety of holiday-related knowledge. Teachers should encourage students this way, students can use the Internet to study independently to better enrich students' 
knowledge in this area. In addition, this approach is to understand students in prep inspection data are used. In the classroom teachers by some students listening materials testing prep completion. Through the student answers Statistics found that students using extracurricular autonomous learning can improve the accuracy of the answers.

After completion of this teaching, the teacher arranged the contents of independent study. Mainly examine students in extracurricular autonomous learning consciousness. In this way the relevant teaching materials to enhance the students a deeper understanding. It also requires students to extracurricular learning experiences and results back to teachers. Teachers then proceed to the next lesson preparation according to the situation of student feedback.

\section{Conclusion}

Constructivism with rich theoretical foundation for teaching a second language have a greater impact on promoting the reform of education has an important guiding significance. Constructivism advocate is an interactive, collaborative, open learning environment, exactly in line with the needs of second language teaching, with adequate emphasis on student-centered learning combined with various elements of the law designed to meet student learning resources, so as to achieve good teaching effect. Our education is in a critical stage of reform and innovation, need instructive theory and constructivism applied to our education innovation and reform to provide the basic concept.

\section{REFERENCE:}

[1] Hao Hongyan. Constructivist Learning Theory and Second Language Teaching Workshop Design [J]. Teaching And Management, 2007,12: 92-93.

[2] Deng Yunjuan. Second Language Acquisition Constructivist Theory [J]. Hunan Agricultural University (Social Science Education Research.), 2008,03: $102+130$.

[3] Yuanping Hua, M. Balfour Beatty Second Language Constructivism Theoretical Framework Entered the Study of Language [J]. Acquisition Literature, 2008,23: 141-142.

[4] Chong Siwei. Language Anxiety and Constructivism-How to Eliminate at Constructivist Teaching Model Language Anxiety [J]. Huainan Vocational and Technical College, 2005,04: 28-30.

[5] Yang Yongfang. Second Language Acquisition Language Input-Inspiration for English Language Teaching to Bring Input from Constructivism [J]. Guangxi Radio and TV University, 2007,01: 38-43.

[6] Guo Mingjing. Internet and Second Language Learning Constructivism [J]. Jiangsu Teachers College (Vocational Education Communication), 2009,09: 105-108.

[7] Ma Linlin. Behaviorism and Constructivism Comparison and Enlightenment Language Teaching [J]. Kaifeng Institute of Education, 2015,06: 49-50. 